\title{
A ESCOLHA DE UM LIVRO DIDÁTICO INTERNACIONAL PARA O CONTEXTO BRASILEIRO: ESTABELECER E ADAPTAR OS CRITÉRIOS DE AVALIAÇÃO
}

\author{
Ruth BOHUNOVSKY - UFPR
}

\section{Resumo}

A escolha de um livro didático a ser utilizado numa instituição de ensino tem consequências que dizem respeito não apenas ao conteúdo temático e gramatical de um curso de língua estrangeira, mas também à sua metodologia. Este artigo tece alguns comentários de natureza geral sobre o papel do livro didático no ensino de línguas estrangeiras, especificamente no caso do alemão no Brasil. Depois disso, discute o trabalho prático de avaliação de livros didáticos e apresenta um catálogo de critérios para a avaliação, que foi elaborado durante uma disciplina de graduação na UFPR intitulada "Alemão como Língua Estrangeira", pela autora e os estudantes, em conjunto. Embora este trabalho se refira mais especificamente à área de alemão, serve também como ponto de partida para um diálogo com outras línguas estrangeiras.

Palavras-chave: livro didático - ensino de línguas estrangeiras - alemão como língua estrangeira.

\section{Zusammenfassung}

Die Auswahl eines Lehrwerks bringt weitreichende Konsequenzen für die Institution und den Unterricht mit sich, da das Lehrwerk nicht nur den grammatikalischen und thematischen Inhalt eines Fremdsprachenkurses vorgibt, sondern oft auch das methodische Vorgehen des Unterrichtenden. Im einführenden Teil der vorliegenden Arbeit wird eher allgemein auf die Rolle des Lehrwerks im Deutsch-als-Fremdsprache-Unterricht in Brasilien eingegangen. Danach wird die praktische Arbeit einer Lehrwerksbegutachtung besprochen und ein Kriterienraster vorgestellt, der im Laufe einer Lehrveranstaltung „Deutsch als Fremdsprache“ an der UFPR erarbeitet wurde, in Zusammenarbeit zwischen der Autorin und den StudentInnen. Obwohl sich die vorliegende Arbeit auf den Bereich Deutsch als Fremdsprache bezieht, möchten wir sie auch als Ausgangspunkt für weiterreichende Dialoge mit anderen Sprachen verstanden wissen.

Schlüsselwörter: Lehrwerk - Fremdsprachenunterricht - Deutsch als Fremdsprache.

\section{O papel do livro didático no ensino de línguas}

O livro didático não determina o sucesso do processo de ensino/aprendizagem de uma língua estrangeira. $\mathrm{O}$ resultado desse processo depende de muitos fatores, entre os quais o 
livro didático utilizado (ou a decisão de trabalhar sem livro didático ${ }^{1}$ ) é apenas um. Contudo, uma vez tomada a decisão de usar um livro didático num curso ou numa determinada instituição de ensino, o material escolhido vai ocupar um lugar influente em vários sentidos: geralmente substitui o planejamento curricular, pois determina de antemão a progressão temática e gramatical, o papel atribuído às diferentes competências comunicativas, assim como, em muitos casos, os procedimentos metodológicos dos professores.

$\mathrm{Na}$ sua tese de doutorado recém concluída, Uphoff aponta a padronização que o livro didático provoca nas escolas, "proporcionando estrutura e uma aparente transparência à grade curricular da instituição, por meio da distribuição das lições em níveis e semestres" (UPHOFF, 2009, p. 62-63) $)^{2}$. A pesquisadora ressalta ainda que "é relativamente raro encontrar uma instituição de ensino de alemão no Brasil que não organiza sua grade curricular dessa forma" (UPHOFF, 2009, p. 63). Ao mesmo tempo, é também o livro didático que, na maioria das vezes, define os procedimentos metodológicos dos professores, seja através dos enunciados no próprio livro texto ou do manual para o professor. De acordo com Krumm - ao se referir a uma pesquisa empírica empreitada por Koskenniemi e Korulainen (1983) -, "os professores raramente têm a capacidade e a disposição de ampliar a margem indicada pelos livros didáticos" (KRUMM, 1994, p. 24) ${ }^{3}$.

Levando em consideração essa relação estreita entre o programa curricular e a metodologia usada em sala de aula com o livro didático, não há dúvida de que a importância deste não deve ser subestimada. Portanto, escolher um livro didático novo para uma determinada instituição deve ser um processo muito bem pensado. Como salienta Prabhu, "materiais (didáticos) novos podem atuar como um instrumento poderoso para mudanças em sala de aula”, já que levam os professores a "mudar seus procedimentos de ensino, de acordo com as exigências do novo material"4 (PRABHU, 2003, p. 22).

\section{O livro didático de alemão como língua estrangeira}

\footnotetext{
${ }^{1}$ Não retomamos, aqui, os argumentos pró e contra o uso de um livro didático versus o ensino sem este. De um modo geral, concordamos com Krumm: "A questão se materiais para o ensino/aprendizagem tendem mais a ajudar ou a causar transtornos só pode ser decidida no contexto, junto com outros fatores" (KRUMM, 1999, p. 119). Entendemos que os argumentos que justificam o uso de um livro didático são, na sua grande maioria, de caráter prático.

${ }^{2}$ Cf., também, Prabhu (2003, p. 22).

3 Para uma discussão mais elucidativa com uma argumentação mais complexa sobre a suposta falta de capacidade de os professores de planejarem suas aulas, cf. sobretudo Uphoff (2009).

${ }^{4}$ Esta e todas as traduções de textos não disponíveis em português são de minha autoria.
} 
Praticamente não há livros didáticos para o ensino de alemão como língua estrangeira produzidos no Brasil. Portanto, é grande a presença de livros internacionais ${ }^{5}$, importados dos países de língua alemã. Lá, a produção de livros didáticos para o processo de ensino/aprendizagem de uma língua estrangeira tem se tornado um ramo econômico bastante rentável. Pode-se notar que, além das grandes editoras ativas há décadas na elaboração e produção de livros didáticos para o alemão (Langenscheidt, Cornelsen, Klett, Hueber), várias editoras menores e, até agora, desconhecidas têm começado a desenvolver esse tipo de material $^{6}$. Assim, encontramos disponível uma variada oferta de títulos diferentes, todos com a mesma promessa: levar ao domínio de uma língua estrangeira ou, no mínimo, até um determinado nível de acordo com o Quadro Comum Europeu para o Ensino de Línguas. Não há livro didático que não destaque, geralmente já na sua capa, que se orienta - até "rigorosamente" (Schritte ${ }^{7}$ - pelo Quadro Comum Europeu. A elaboração de livros didáticos se fundamenta, portanto, não apenas em determinados conceitos metodológicos, mas também em concepções didático-políticas. No caso do Quadro Comum Europeu, vale ressaltar que ele recomenda uma abordagem metodológica comunicativa (UPHOFF, 2009, p. 80).

Se a grande influência do Quadro Comum Europeu (em razão também de este servir como referência em exames oficiais) gerou uma maior homogeneização dos conteúdos didáticos, os livros, por sua vez, parecem se dirigir a um público de aprendizes de alemão supostamente homogêneo. Existem livros que se dirigem a um público mais limitado (por exemplo, para profissionais nas áreas de turismo ou de saúde) ou que estão disponíveis em diversas versões (por exemplo, para o ensino de alemão como segunda língua ou como língua estrangeira ${ }^{8}$. Nesse sentido, vale a pena citar duas das conclusões às quais chega Groß numa recente análise comparativa entre livros didáticos de alemão que se dirigem a um público alvo mais geral e outros que se dirigem a especialistas na área de economia. A pesquisadora frisa que, "baseadas em argumentos econômicos das editoras, as definições dos grupos alvo de livros didáticos especializados na área de economia são (muitas vezes) bastante gerais" (GROSS, 2009, p. 144). Além disso, ela comenta que as diferenças entre os

\footnotetext{
${ }^{5}$ Entendemos aqui um livro didático como "internacional" quando este se dirige ao público mundial.

${ }^{6}$ A crescente presença de editoras menores no mercado de livros didáticos para o ensino de alemão como língua estrangeira pôde ser constatada, por exemplo, no XIV. Internationale Tagung der Deutschlehrerinnen und Deutschlehrer (XIV Encontro Internacional de professores e professoras de alemão), nas cidades de Jena e Weimar, em agosto de 2009, onde estavam presentes vários representantes de pequenas editoras até então desconhecidas.

${ }^{7}$ Cf. <http://www.hueber.de/seite/info_index_sri>, acesso em 6 de novembro de 2009.

${ }^{8}$ A editora Hueber, por exemplo, lançou os livros didáticos Schritte ("para aprendizes que estejam planejando uma estada mais longa num país de língua alemã ou que já vivam num país de língua alemã”) e Schritte International ("para aprendizes que conhecem os países de língua alemã apenas 'por fora'"). (<http://www.hueber.de/seite/pg_info_fuerwen_sri>, acesso em 23 de outubro de 2009).
} 
livros didáticos gerais e os especializados encontram-se apenas na idealização de suas formas, pois "na realidade as diferenças são apenas pontuais" (GROSS, 2009, p. 144).

Se nem os livros didáticos que se dirigem a um público bem definido (profissionais na área de economia) se diferenciam substancialmente dos livros gerais, estes entre si mostram semelhanças ainda maiores. Percebe-se isso, por exemplo, nas definições dos públicos alvo aos quais se dirigem. Na contracapa do livro didático studio $d$ podemos ler, por exemplo, que o livro se dirige "a adultos sem conhecimentos prévios que estudam ou num país de língua alemã ou no exterior", independentemente se precisam da língua alemã para fins profissionais ou para objetivos de lazer ou turismo (FUNK E OUTROS, 2009) ${ }^{9}$. Seria difícil formular uma definição mais generalizante e vaga - e, consequentemente, pouco útil para se escolher o livro mais adequado para um determinado grupo. A descrição que encontramos no site da editora Schubert, que lançou Begegnungen - Deutsch als Fremdsprache, também pode ser considerada como sintomática dessa falta de especificação no que tange ao público alvo: segundo a editora, trata-se de um "livro didático moderno e comunicativo" que se "dirige a aprendizes adultos que querem aprender alemão de maneira rápida e eficiente" ${ }^{, 10}$. Dificilmente encontrar alguém, entre todos os adultos no mundo que pretendem estudar a língua alemã, que não se encaixe nesse perfil. Cabe a pergunta: onde está a "orientação pelo público alvo específico" (Zielgruppenorientierung), tão exigida em discussões teóricas da área? Não apenas na área de alemão, tem se defendido desde os anos 80 a necessidade de se repensar - e, eventualmente, suspender - a exportação de métodos e livros didáticos produzidos nos países de origem da língua alvo para o mundo afora. Outras vezes, tem-se exigido, pelo menos, a adaptação dos livros didáticos internacionais para as condições reais onde a língua é ensinada (cf. KRUMM, 1999, p. 121). No que tange ao ensino de alemão no Brasil, depois de algumas tentativas nesse sentido - por exemplo, o glossário em português do Brasil do livro Themen (OLIVEIRA; VOORSLUYS, 1986) - é evidente o domínio dos livros internacionais, isto é, importados dos países de língua alemã, sem nenhuma adaptação específica para o público brasileiro ${ }^{11}$.

\footnotetext{
${ }^{9}$ Com uma formulação muito semelhante, a definição do público alvo como "adultos e jovens a partir de 16 anos que querem aprender alemão, dentro ou fora de um dos países de língua alemã" pode ser encontrada em vários livros didáticos na área de alemão como língua estrangeira (p.ex. Schritte international, Berliner Platz. Neu, Optimal).

${ }^{10}$ Cf. <http://www.schubert-verlag.de/index.php?st=1>, acesso em 28 de outubro de 2009.

${ }^{11}$ Uma exceção é o livro didático Blaue Blume (EICHHEIM E OUTROS, 2006), cuja forma básica foi concebida na Alemanha pela editora Hueber, mas cujo texto foi traduzido para diversas línguas, inclusive o português (pela editora da Unicamp). Pode-se mencionar também o livro didático Alemão para brasileiros: com João Ubaldo Ribeiro em Berlim (BOHUNOVSKY; BOLOGNINI), em elaboração desde 2003 e ainda não publicado.
} 
A grande semelhança entre os livros didáticos disponíveis não se restringe apenas à definição do público alvo, mas está relacionada a muitos outros aspectos, como polemiza Hermann Funk, um dos grandes nomes da área do ensino de alemão como língua estrangeira:

\begin{abstract}
Numa primeira impressão, a maioria dos livros didáticos das editoras alemãs vem se assemelhando em um grau nunca visto antes. Praticamente, todo mundo já descobriu a importância da fonética e o valor de resumos gramaticais no livro didático. Quase todos os livros vêm com CDs e oferecem sites na internet. Todos se referem explicitamente aos níveis estabelecidos pelo Conselho Europeu. Quase todos mostram preferência pelo mesmo tipo de exercícios e encomendam suas fotos nas mesmas agências. Os designers das agências seguem as mesmas tendências em relação a cores, fotos e títulos: pessoas jovens, dinâmicas e alegres, de diferentes origens. (FUNK 2004: 41).
\end{abstract}

Essa afirmação de Funk sobre a grande semelhança entre os livros didáticos não deve ser entendida de maneira absoluta, como o próprio autor sugere ao longo do trabalho citado. Vários estudos têm apontado diferenças substanciais entre publicações recentes, no que diz respeito, por exemplo, à tematização da realidade plurilinguística da Europa, da "autenticidade" dos textos citados, da presença de estratégias de aprendizagem etc. (FAISTAUER, 2006). No entanto, para perceber tais diferenças, não é suficiente se ater às definições dos públicos alvo mencionados, nem às informações dadas pelos autores nas introduções dos livros onde se encontram destacados sempre os mesmos termos-chave: Quadro Europeu Comum, comunicativo, eficiente etc. Faz-se necessária uma análise mais aprofundada.

\title{
Análise empírica vs. análise hermenêutica
}

Como proceder então para escolher o livro didático mais adequado para uma determinada instituição ou para um público alvo bem definido? No caso das instituições públicas, valem as diretrizes do MEC. No caso de escolas de língua particulares, do ensino universitário e das escolas de aplicação das instituições do ensino superior, vale a decisão dos responsáveis. Quais critérios seguir?

Testar um livro didático apenas de maneira empírica é um empreendimento que exige muito tempo, já que os resultados do trabalho só serão vistos em longo prazo. Portanto, um estudo comparativo torna-se muitas vezes inexequível. Além disso, concordamos com Krumm que contraria a consideração de que apenas a experiência permitira "uma avaliação adequada" e adverte que a experiência poderia, também, produzir o efeito de "tornar alguém cego em relação a novas abordagens e possibilidades" (KRUMM, 1994, p. 25). 
Nos países de língua alemã, a análise e/ou crítica sistemática de livros didáticos de alemão como língua estrangeira existe desde os anos 70, época em que ocorreu um aumento grande na oferta de títulos disponíveis com concepções didáticas às vezes diametralmente opostas. Membros de algumas instituições representativas para o ensino de alemão (por exemplo, o Instituto Goethe, o Instituto para a Língua Alemã etc.) desenvolveram, em 1977, o Mannheimer Gutachten (parecer de Mannheim) (ENGEL, 1977), uma avaliação geral e pretensiosamente "objetiva" de um número grande de livros didáticos. Apesar dessa pretensão, podemos ler, já no texto introdutório dessa publicação, que não existe algo como "o livro didático ideal", mas que existem "diversos objetivos e condições de ensino" que implicam diferentes “concepções de livro didático” (MANNHEIMER GUTACHTEN 1977, p. 10). Nos anos 80 , o tema do público alvo específico ganhou mais espaço e recebeu mais atenção devido a alguns acontecimentos como, por exemplo, os trabalhadores que migravam para a Alemanha (BARKOWSKI, 1980). Em 1990, foi apresentado o Stockholmer Kriterienkatalog (catálogo de critérios de Estocolmo), cujo enfoque foram as especificidades regionais do aprendizes (KRUMM, 1994).

De um modo geral, pode-se afirmar que os livros didáticos atuais utilizam "abordagem integrativa": eles não procuram mais uma aplicação stritu senso de um determinado método de ensino, mas integrar elementos de diferentes abordagens teóricas. Pode-se resumir o teor das discussões dos últimos anos na área de análise de livros didático de alemão como língua estrangeira da seguinte maneira: não existe a possibilidade de se definir algum livro didático como o "melhor". Um rol de fatores variáveis, de natureza pessoal e situacional, deve ser levado em consideração na hora de se escolher um livro didático - o que impossibilita, em última instância, pronunciamentos gerais ou "objetivos" sobre a sua qualidade. Essa afirmação não significa, porém, que se trate apenas de um processo ou uma avaliação subjetiva, sem critérios válidos a serem estabelecidos e seguidos. De acordo com Funk,

apesar das restrições [...], resultam, do ponto de vista didático, alguns indícios e exigências de qualidade em relação aos meios de ensino/aprendizagem. Mas a importância que lhes cabe na escolha de um meio de ensino, em uma situação concreta de planejamento numa instituição ou numa escola de línguas, não pode ser postulada independentemente do corpo docente e dos aprendizes. (FUNK, 2004, p. 44).

Os teóricos defendem atualmente uma "análise hermenêutica de livros didáticos", isto é, uma integração dos conhecimentos teóricos e científicos com as experiências práticas e as exigências desejáveis no campo didático (KRUMM, 1994, p. 25). Para tal procedimento, têm 
sido desenvolvidas várias listas com critérios, baseados nas discussões teóricas da área, a partir dos quais uma análise de livros didáticos se tornaria mais transparente e compreensível, mesmo para quem não participa do processo de avaliação diretamente. Devese distinguir entre aquelas listas que fornecem uma base para uma avaliação acadêmica e as que são entendidas como ponto de partida para escolha de um livro didático entre vários, isto é, um livro didático que será usado no ensino com um público alvo bem definido. O presente trabalho surgiu de um processo de avaliação do segundo tipo.

O trabalho com qualquer lista de critérios decisivos implica um risco: embora estes constituam uma base útil para comparações entre livros didáticos, sua objetividade pode ser apenas aparente. Como ilustra Funk, as perguntas que constam numa lista de critérios, muitas vezes, partem de premissas teóricas não explicitadas e talvez desconhecidas por parte daqueles que efetuam a análise. Ele cita dois exemplos: "O material contém exercícios mais abertos que levam a um uso mais aberto com a língua? Existem exercícios que possibilitam uma relação mais lúdica e criativa com a língua?" Como argumenta Funk, essas perguntas pressupõem tanto que se saiba avaliar o grau de abertura de um exercício quanto que seja desejável a presença desse tipo de exercícios: Um trabalho sem a devida preparação e o conhecimento teórico pode-se tornar, assim, “contraprodutivo” (FUNK, 1994, p. 109-11).

\section{O trabalho com os critérios: da crítica à prática}

No segundo semestre de 2009, ministramos uma disciplina sobre crítica e análise de livros didáticos. Definimos como objetivo do curso a escolha de um novo livro didático para ser utilizado no Celin, provavelmente a partir do segundo semestre de 201012. A avaliação e a escolha deviam acontecer, em sala de aula, durante um trabalho em conjunto, da docente que também é coordenadora da área de alemão no Celin com os estudantes - que, por sua vez, são também os professores que ministram os cursos de alemão no Celin e têm, assim, muita familiaridade com o público alvo específico.

Partindo-se da premissa de que a simples aplicação de uma lista de critérios sem a devida preparação teórica e discussão sobre os itens em questão não poderia levar a uma escolha crítica de um livro didático, foi tomada a decisão de tornar, num primeiro momento,

\footnotetext{
12 O Celin (Centro de Línguas e Interculturalidade) funciona como uma escola de aplicação da UFPR (Universidade Federal do Paraná), Curitiba. Nessa instituição, a escolha do livro didático cabe ao coordenador de ensino de cada língua e todos os professores necessariamente trabalham com o mesmo material. É o livro que determina o conteúdo do curso, e para cada nível (alemão 1 a alemão 7) há uma determinada sequência de lições correspondente.
} 
a lista de critérios em si o objetivo das discussões em sala de aula. Ou seja, iniciamos o trabalho de análise com uma crítica de diversos catálogos de critérios. Nesse momento, insistimos especialmente em discussões sobre a relevância (ou a eventual falta de relevância) para o ensino no Brasil de certos aspectos do Quadro Comum Europeu que, muitas vezes, são aceitos também por aqui, embora se refiram claramente à situação europeia de ensino (por exemplo, o plurilinguísmo ou o peso grande na comunicação cotidiana oral e em aspectos pragmáticos). Entendemos que a situação do ensino de alemão no Brasil difere da situação europeia, sobretudo no sentido de que os nossos aprendizes não se preparam, na sua grande maioria, para uma viagem imediata para a Europa. Além disso, têm seu contato com a língua e aspectos culturais do alemão limitados ao tempo em sala de aula, o que implica uma atenção especial para o papel e a função de questões culturais. Assim, aspectos pragmáticos da comunicação cotidiana perdem importância em relação a questões relacionadas à aprendizagem cultural num sentido mais amplo13.

Depois desse trabalho de crítica, iniciou-se o processo de elaboração de um catálogo de critérios relevantes para o nosso público alvo específico. Esse público constitui-se, na sua maioria, mas não exclusivamente, de estudantes universitários brasileiros das mais diversas áreas que estudam alemão por motivos profissionais ou privados e que - como já foi dito não se preparam para uma viagem imediata para um dos países de língua alemã. Tais reflexões explicam a grande importância que atribuímos às questões relacionadas aos aspectos culturais no catálogo (veja anexo).

É mister lembrar que o Celin funciona como uma escola de aplicação da UFPR, ou seja, é um lugar onde professores em formação fazem as suas primeiras experiências práticas em sala de aula - sob constante orientação dos docentes responsáveis da UFPR. Desse modo, o livro didático utilizado deveria apresentar não apenas uma boa base para o processo de aprendizagem dos aprendizes, mas também para a formação didática dos docentes. Em termos mais concretos, isso significa que o livro a ser escolhido não deveria restringir a atuação do professor em sala de aula, mas valorizar seu trabalho autônomo, já que todos os professores iniciantes são acompanhados permanentemente por docentes da UFPR da área de ensino de língua estrangeira. Entendemos que um livro didático "fechado" (ou seja, que predefine claramente os procedimentos metodológicos do professor) não favorece seu processo de formação, pois contribui para uma postura pouco autônoma por parte do

\footnotetext{
${ }^{13}$ Aqui, o significado de aprendizagem cultural deve ser entendido conforme as definições propostas por Altmayer (2004).
} 
professor14. Daríamos preferência a um livro didático que fosse entendido pelos seus autores como um "roteiro" e que previsse espaço para sua adaptação ao âmbito específico onde será usado.

De todos os catálogos de critérios que passaram por nossa análise, apenas um, elaborado por Funk (2004), prevê explicitamente uma discussão prévia dos docentes sobre a importância (ou a eventual falta de importância) dos diversos aspectos alistados no contexto concreto para o qual se procura um livro didático. No catálogo, em anexo, constam os pesos dados para os respectivos pontos no âmbito da disciplina acima mencionada. Esses pesos representam o resultado das reflexões teóricas e de ordem prática desenvolvidas em sala de aula. Desse modo, constituem-se em uma adaptação de um catálogo para um contexto brasileiro bem definido. Constam, nesse mesmo catálogo, além das perguntas que dizem respeito ao material, indicadores que podem ajudar a limitar o número de interpretações divergentes em relação às questões levantadas. Permite-se, assim, uma avaliação bastante transparente, compreensível, adaptada à realidade da instituição e às características dos docentes e aprendizes em questão. Por esses motivos, decidimos nos basear no catálogo elaborado por Funk (2004), sem deixar de fazer as alterações e reformulações que consideramos necessárias para o nosso contexto.

O próprio Funk sugere que seu catálogo seja entendido como "instrumento de trabalho aberto e ampliável, como ajuda de estruturação para a discussão colegial dos docentes e não como um documento normativo" (FUNK, 2004, p. 44). O primeiro passo da avaliação com base no referido catálogo deve ser uma discussão e uma ampliação do mesmo, de acordo com as necessidades e os interesses concretos. O catálogo anexado ao presente trabalho é o resultado dessa adaptação para o nosso contexto. Algumas questões do catálogo original de Funk (2004) foram eliminadas, outras acrescentadas (e devidamente destacadas). Desse modo, o catálogo apresentado constitui uma proposta para a avaliação de outros livros didáticos, inclusive de outras línguas, desde que seja feita a devida adaptação ao novo contexto. Depois da ampliação, deve haver as atribuições de peso (de $0=$ irrelevante até $2=$ muito relevante) para as perguntas, dependendo, novamente, das necessidades e dos interesses de cada instituição. O próximo passo seria a avaliação de diversos livros didáticos para se proceder a uma escolha. Não se pode esquecer que a escolha final de um livro com essa finalidade não deve estar baseada apenas na nota alcançada, mas, principalmente, numa nova reflexão sobre o peso real dos critérios avaliados. Desse modo, o catálogo não pode ser

\footnotetext{
${ }^{14}$ Cf. Prabhu (2003).
} 
visto como uma base para um cálculo matemático "objetivo" que levaria à escolha do livro ideal, mas como uma base para discussão e reflexão.

Funk entende seu catálogo como ponto de partida para escolher um livro didático, ou seja, como voltado para o trabalho prático. Outras análises de livros didáticos têm um viés mais acadêmico-teórico e se aprofundam, muitas vezes, em um ou poucos aspectos específicos - fato que não as torna menos importantes ou necessárias, mas "muito pouco decisivas" na escolha real de um livro num determinado contexto, como admite Faistauer (2006, p. 12) - ela própria autora de um estudo acadêmico. Levando em consideração que, no projeto que deu início à análise aqui referida, o objetivo foi de natureza prática, justifica-se certamente usar o catálogo de Funk como ponto de partida - sem, com isso, se pretender negar a importância de estudos menos abrangentes e mais aprofundados.

É importante ressaltar ainda que, sobretudo desde a ascensão das novas mídias no ensino de línguas estrangeiras, o livro didático não deve ser entendido como uma oferta completa para o ensino em sala de aula. Entendemos um livro didático como um "roteiro" para o ensino, um ponto de referência para o docente planejar as aulas e também para os alunos planejarem seu processo de aprendizagem. Desse modo, o livro didático não precisa oferecer tudo; até mesmo porque muitas informações atualizadas estão disponíveis em páginas específicas da internet. Por outro lado, como aponta Funk, "baixar da internet exercícios gramaticais sem contexto, que antigamente eram reproduzidos por copiadoras, ainda não representa nenhum avanço" (FUNK, 2004, p. 43).

Essas reflexões foram feitas durante as discussões em sala de aula, assim como outras não especificadas aqui - desde o poder aquisitivo dos nossos alunos até a necessidade de equilíbrio entre as habilidades comunicativas, as representações das diversas variações da língua alemã, a progressão circular de gramática, o papel da fonética etc. De algum modo, no catálogo em anexo, todos esses fatores foram considerados nas formulações dos critérios e na atribuição de pesos a cada um deles.

\section{Referências}

ALTMAYER, Claus. Kultur als Hypertext: Zu Theorie und Praxis der Kulturwissenschaft im Fach Deutsch als Fremdsprache. München: Iudiucum, 2004.

BARKOWSKI, Hans et. al (org.). Deutsch für ausländische Arbeiter. Gutachten zu ausgewählten Lehrwerken. Mainz, 1980.

BOHUNOVSKY, Ruth, BOLOGNINI, Carmen Zink. Alemão para brasileiros: Com João Ubaldo Ribeiro em Berlim. Não publicado. 
EICHHEIM, Hubert et al. Blaue Blume - Deutsch als Fremdsprache. Trad. Paulo Oliveira e Susana Kampff Lages. Campinas: Unicamp, 2006.

ENGEL, Ulrich et al. (org.). Mannheimer Gutachten zu ausgewählten Lehrwerken Deutsch als Fremdsprache. Heidelberg: Julius Groos Verlag, 1977.

FAISTAUER, Renate. "Neue Lehrwerke auf dem methodisch-didaktischen Prüfstand". ÖDaF-Mitteilungen, Viena, 22/2, p. 10-27, 2006.

FUNK, Hermann. „Arbeitsfragen zur Lehrwerksanalyse“. In: KAST, Bernd; NEUNER, Gerhard (org.). Zur Analyse, Begutachtung und Entwicklung von Lehrwerken. Berlin: Langenscheidt, 1994. p. 105-111.

FUNK, Hermann. „Qualitätsmerkmale von Lehrwerken prüfen - ein Verfahrensvorschlag“. Babylonia, 3/04, 2004. Disponível em: <www.babylonia-ti.ch>. Acesso em: 13 out. 2009.

FUNK, Hermann et al. studio d - Deutsch als Fremdsprache. Berlin: Cornelsen, 2009.

GROSS, Claudia. “'Viel Lärm um nichts?’ Fachsprachenlehrwerke im Spannungsfeld zwischen Theorie und Praxis. Eine vergleichende Analyse berufs- und fachbezogener DaFLehrwerke aus dem Bereich Wirtschaft“. Pandaemonium Germanicum, 13, São Paulo, p. 127-145, 2009. Disponível em:

$<$ www.fflch.usp.br/dlm/alemao/pandaemoniumgermanicum>. Acesso em: 13 de novembro de 2009.

KAST, Bernd; NEUNER, Gerhard (org). Zur Analyse, Begutachtung und Entwicklung von Lehrwerken. Berlin: Langenscheidt, 1994.

KRUMM, Hans-Jürgen. „Stockholmer Kriterienkatalog“. In: KAST, Bernd; NEUNER,

KRUMM, Hans-Jürgen. „Zum Stand der Lehrwerksforschung aus der Sicht des Deutschen als Fremdsprache“. In: BAUSCH, K. et al. (org.). Die Erforschung von Lehr- und Lernmaterialien im Kontext des Lehrens und Lernens. Tübingen: Narr, 1999. p. 119-128.

OLIVEIRA, Henrique Silveira de; VOORSLUYS, Maria Helena. Themen 1 - Glossar Portugiesisch Brasilien. São Paulo: Pedagógica Universitário - EPU, 1986.

PRABHU, N. S. „Should Materials be Prescribed?“. Bangalore, Índia, 2003 (mimeo).

UPHOFF, Dörthe. O poder do livro didático e a posição do professor no ensino de alemão como língua estrangeira. Tese (Doutorado em Linguística Aplicada) - Instituto de Estudos da Linguagem, Universidade Estadual de Campinas, Campinas, 2009. 
ANEXO

\begin{tabular}{|c|c|c|c|c|}
\hline & Uma proposta para a avaliação de livros didáticos ${ }^{15}$ & & & \\
\hline & $\begin{array}{l}\text { Características de qualidade e indicadores } \\
\text { A: } 0=\text { irrelevante } 1=\text { relevante } 2=\text { muito relevante } \\
\text { B: } 0=\text { inexistente/ruim } 1=\text { sim/bom } \\
\quad 2=\text { sim/excelente }\end{array}$ & $\begin{array}{l}\text { A: } \\
\text { peso }\end{array}$ & $\begin{array}{l}\text { B: } \\
\text { nota }\end{array}$ & SOMA \\
\hline Q1 & $\begin{array}{l}\text { Material de suporte e concepção da mídia } \\
\text { 1.1. CDs disponíveis para os aprendizes? (p. ex., CD } \\
\text { grátis no livro) } \\
\text { 1.2. Página própria do livro didático na internet (com } \\
\text { exercícios online, endereços de internet e dicas } \\
\text { didáticas) } \\
\text { 1.3. CD-Rom grátis } \\
\text { 1.4. Descrição da concepção da mídia no livro para o } \\
\text { professor } \\
\text { 1.5. Livro para o professor com ampla oferta de } \\
\text { informações e dicas culturais, gramaticais e } \\
\text { didáticas, atualizadas e em diálogo com as } \\
\text { teorias correntes }\end{array}$ & $\begin{array}{l}. .2 \ldots \\
\\
. .1 \ldots \\
. .0,5 \\
. .1 \ldots\end{array}$ & ............... & an..... \\
\hline Q2 & $\begin{array}{l}\text { Concordância curricular } \\
\text { 2.1. Orientado pelo Quadro Comum Europeu } \\
\text { Indicadores: os volumes do livro didático são adequados } \\
\text { aos níveis de proficiência (A1, A2)? As definições dos } \\
\text { níveis de competência aparecem de maneira } \\
\text { transparente como elemento central tanto no sumário } \\
\text { quanto nas lições? Promove-se a autonomia do aprendiz } \\
\text { através do tipo de tarefa? Segue-se às indicações } \\
\text { gramaticais (quantidade, separação, nivelamento) dos } \\
\text { níveis de proficiência (sem exageros)? O trabalho de } \\
\text { portfólio, avaliação e autoavaliação são partes } \\
\text { integradas do livro? } \\
\text { 2.2. Existe concordância curricular relativa a outros } \\
\text { currículos relevantes e exigências institucionais (P. ex., } \\
\text { no que tange a programas de escolas e instituições e a } \\
\text { indicações pedagógicas)? }\end{array}$ & $\ldots 0 \ldots$ & & ........ \\
\hline Q3 & $\begin{array}{l}\text { Concordância com relação à própria instituição } \\
\text { 3.1. O conteúdo do material é adequado para o tempo de } \\
\text { aula disponível e as metas a serem alcançadas? } \\
\text { Indicador: informações no livro do professor, estimativa } \\
\text { com base em uma unidade } \\
\text { 3.2. Qualificação dos professores para o trabalho com o } \\
\text { material } \\
\text { Indicadores: livro didático aberto que valoriza o } \\
\text { trabalho autônomo e individual do professor }\end{array}$ & $\ldots 2 \ldots$ & & ........ \\
\hline
\end{tabular}

15 Baseada em Funk (2004). Os trechos destacados não constam no catálogo do referido autor; foram formulados e incluídos por nosso grupo de trabalho.

${ }^{16}$ Que importância tem esse aspecto para mim e/ou para a minha instituição? 


\begin{tabular}{|c|c|c|c|c|}
\hline & 3.3 Relação custo/benefício & $\ldots 2$. & $\ldots \ldots$ & $\ldots \ldots$. \\
\hline Q4 & $\begin{array}{l}\text { Correspondência didática atualizada em relação à } \\
\text { competência auditiva } \\
\text { 4.1. A oferta de exercícios de audição no material é } \\
\text { grande e diferenciada e considera as definições dos } \\
\text { níveis de competência do Quadro Europeu Comum } \\
\text { Indicadores: existem exercícios de audição no livro } \\
\text { texto e no livro de exercícios e também exercícios de } \\
\text { audição para vocabulário e gramática } \\
\text { 4.2 O livro contém textos auditivos autênticos (não } \\
\text { produzidos com fins didáticos) } \\
\text { 4.2. Há exercícios que preparam, que conduzem e que } \\
\text { testam a compreensão do aprendiz } \\
\text { Indicadores: sequência de desoneração, de dedução de } \\
\text { informações e de testes de compreensão } \\
\text { 4.3. A competência auditiva é praticada em nível geral e } \\
\text { seletivo } \\
\text { Indicadores: perguntas gerais antes da audição dos } \\
\text { textos, tarefas para a compreensão seletiva das } \\
\text { informações } \\
\text { 4.4. Há também textos auditivos com fins lúdicos, que } \\
\text { promovem uma relação emocional positiva com a língua } \\
\text { 4.5. O livro oferece as transcrições dos textos de } \\
\text { áudio }\end{array}$ & $\begin{array}{l}.1,5 . . \\
\ldots 1 \ldots \\
\ldots 1 \ldots\end{array}$ & $\begin{array}{l}\ldots \ldots . . \\
\ldots \ldots . . \\
\ldots \ldots . .\end{array}$ & $\begin{array}{l}\ldots \ldots . \\
\ldots \ldots . \\
\ldots \ldots\end{array}$ \\
\hline Q5 & $\begin{array}{l}\text { A competência de leitura } \\
\text { 5.1. A oferta de textos considera as indicações do } \\
\text { Quadro Europeu Comum } \\
\text { Indicador: as indicações referentes aos gêneros textuais } \\
\text { são levadas em conta nas lições } \\
\text { 5.2. Há exercícios que preparam, que conduzem e que } \\
\text { testam a compreensão do aprendiz } \\
\text { Indicadores: sequência de desoneração, de dedução de } \\
\text { informações e de testes de compreensão } \\
\text { 5.3. Treinam-se estratégias de leitura em nível geral e } \\
\text { seletivo } \\
\text { Indicadores: perguntas gerais antes da leitura do texto, } \\
\text { tarefas para a dedução de informações seletivas, dicas } \\
\text { explícitas de estratégias de leitura }\end{array}$ & $\ldots 1 \ldots$ & ....... & ....... \\
\hline Q6 & $\begin{array}{l}\text { A competência comunicativa } \\
\text { 6.1. As indicações dialógicas correspondem às } \\
\text { exigências do Quadro Comum Europeu } \\
\text { Indicadores: as definições das competências são citadas } \\
\text { no sumário } \\
\text { 6.2. Os aprendizes também falam como "eles próprios", } \\
\text { em todas as fases (treinamento da atuação comunicativa } \\
\text { ativa) } \\
\text { Indicadores: as frases de exercício podem ser usadas } \\
\text { pelos aprendizes em contextos relevantes para eles. Em } \\
\text { vez de: "X sai de casa às } 7 \text { da manhã"; geralmente, "eu } \\
\text { saio de casa..." }\end{array}$ & $. .0,5 .$. & ....... & ....... \\
\hline
\end{tabular}




\begin{tabular}{|c|c|c|c|c|}
\hline & $\begin{array}{l}\text { 6.3. Há uma oferta contínua de exercícios e tarefas para } \\
\text { a automatização da fluência linguística } \\
\text { Indicadores: exercícios (p. ex., lúdicos) com alta } \\
\text { probabilidade de estruturas iguais e frequentes na } \\
\text { comunicação } \\
\text { 6.4. A apresentação dos diálogos leva em } \\
\text { consideração as especificidades da linguagem falada } \\
\text { e os vários registros de língua } \\
\text { Indicador: os diálogos não são construídos } \\
\text { didaticamente ou de acordo com a progressão } \\
\text { gramatical. A sua estruturação se aproxima da fala } \\
\text { natural }\end{array}$ & $. .1,5 .$. & ........ & ....... \\
\hline Q7 & $\begin{array}{l}\text { A competência de escrever } \\
\text { 7.1. Os aprendizes escrevem, desde o início, como "eles } \\
\text { próprios"? } \\
\text { Indicadores: promoção da competência de escrever } \\
\text { textos pessoais } \\
\text { 7.2. O livro oferece estratégias para a escrita } \\
\text { Indicador: exercícios com estruturas da língua } \\
\text { escrita frequentes em diversos gêneros textuais (p. } \\
\text { ex., carta formal e informal, e-mail) }\end{array}$ & $\ldots 1 \ldots$ & $\ldots \ldots$ & ....... \\
\hline Q8 & $\begin{array}{l}\text { Concepção de exercícios e tarefas } \\
\text { 8.1 Segue-se o conceito do treinamento integrado de } \\
\text { competências } \\
\text { Indicadores: as competências não são treinadas } \\
\text { separadamente, há também sequências que envolvem } \\
\text { todas as competências } \\
\text { 8.2. O livro oferece tanto tarefas (ações linguísticas } \\
\text { "relacionadas à vida") quanto exercícios (competências } \\
\text { isoladas)? } \\
\text { Indicadores: percebe-se uma progressão de exercícios } \\
\text { para tarefas comunicativas. A proporção entre os } \\
\text { exercícios e as tarefas é equilibrada (p. ex., não há } \\
\text { excesso de exercícios de lacunas ou de exercícios sobre } \\
\text { pontos formais da língua). Há propostas para projetos. } \\
\text { 8.3. É previsto o trabalho diferenciado, em sala de } \\
\text { aula, para aprendizes com diferentes níveis de } \\
\text { competência na língua alvo (diferenciação interna) } \\
\text { Indicador: exercícios para diferentes níveis de } \\
\text { competência linguística numa mesma lição, dicas no } \\
\text { livro para o professor }\end{array}$ & $\ldots 2 \ldots$ & …...... & ........ \\
\hline Q9 & $\begin{array}{l}\text { Gramática e fonética } \\
\text { 9.1. A competência gramatical é sempre praticada } \\
\text { juntamente com a competência de ação comunicativa } \\
\text { Indicadores: novas estruturas relacionadas "com a vida } \\
\text { cotidiana" são apresentadas. As formas gramaticais são } \\
\text { utilizadas para formular declarações de conteúdo, não } \\
\text { para frases de treinamento sem sentido. Todos os } \\
\text { exercícios enfocam o conteúdo. } \\
\text { 9.2. A relação estabelecida entre ação comunicativa, }\end{array}$ & $\ldots 2 \ldots$ & ......... & ........ \\
\hline
\end{tabular}




\begin{tabular}{|c|c|c|c|c|}
\hline & $\begin{array}{l}\text { significado e gramática resulta no fato de que estes } \\
\text { sistemas não são apresentados em bloco de uma só vez, } \\
\text { mas sempre fragmentados, em partes, de acordo com o } \\
\text { seu uso. } \\
\text { Indicadores: os verbos modais não são apresentados } \\
\text { num bloco, os verbos com prefixos separáveis e } \\
\text { inseparáveis não são apresentados juntos. As frases } \\
\text { subordinadas são apresentadas de acordo com seu } \\
\text { significado (p. ex., separação de frases causais e } \\
\text { consecutivas) } \\
\text { 9.3. As pesquisas sobre as sequências naturais de } \\
\text { aquisição de línguas são levadas em consideração } \\
\text { Indicadores: tolerância de erros de declinação nos níveis } \\
\text { iniciais, dicas no livro para o professor sobre as } \\
\text { sequências de aquisição } \\
\text { 9.4. Há dicas e estratégias para os aprendizes } \\
\text { elaborarem, eles mesmos, as regras da língua } \\
\text { Indicadores: há sequências indutivas para juntar, } \\
\text { organizar e sistematizar estruturas linguísticas, dicas de } \\
\text { estratégias de aprendizagem } \\
\text { 9.5. A gramática é também conteúdo para exercícios de } \\
\text { automatização } \\
\text { Indicador: exercícios com conteúdo pragmático e com } \\
\text { alta frequência de repetição, nos quais os aprendizes } \\
\text { podem reagir rapidamente, sem pensar muito. } \\
\text { 9.6. A progressão gramatical é cíclica } \\
\text { Indicador: os aspectos gramaticais apresentados são } \\
\text { retomados frequentemente ao longo do livro } \\
\text { 9.7. Há um resumo dos aspectos gramaticais mais } \\
\text { importantes do volume para o estudo autônomo e a } \\
\text { sistematização } \\
\text { Indicador: os aspectos gramaticais são apresentados } \\
\text { aos poucos ao longo das lições, há um resumo geral } \\
\text { no final do livro } \\
\text { 9.8. Os exercícios de fonética são apresentados em } \\
\text { relação com os exercícios de conteúdo e não de maneira } \\
\text { isolada. } \\
\text { Indicador: integração dos exercícios de fonética e de } \\
\text { entonação a outros exercícios (em vez de apresentados } \\
\text { isoladamente em um bloco exclusivo) } \\
\text { 9.9. No livro, encontram-se textos auditivos } \\
\text { representativos para as diversas variações da língua } \\
\text { alvo } \\
\text { 9.10. No livro, encontram-se atividades que } \\
\text { favorecem os diferentes tipos de aprendizes } \\
\text { (cognitivo, auditivo etc.) }\end{array}$ & $\begin{array}{c}\ldots 2 \ldots \\
\\
\\
\ldots 1 \ldots \\
\ldots 2 \ldots\end{array}$ & $\begin{array}{l}\ldots \ldots \\
\ldots \ldots . .\end{array}$ & $\ldots \ldots$ \\
\hline Q10 & $\begin{array}{l}\text { Trabalho com o vocabulário } \\
\text { 10.1. O livro didático contém propostas para a } \\
\text { diferenciação do vocabulário de recepção e de produção } \\
\text { Indicador: constam no glossário as respectivas }\end{array}$ & & & \\
\hline
\end{tabular}




\begin{tabular}{|c|c|c|c|c|}
\hline & $\begin{array}{l}\text { indicações. } \\
\text { 10.2. A oferta de vocabulário orienta-se nos campos de } \\
\text { termos que constam nas publicações referentes ao } \\
\text { Quadro Europeu Comum, mas é aberta. Os aprendizes } \\
\text { participam da escolha do vocabulário a ser estudado. } \\
\text { Indicador: o material contém ofertas (apoiadas } \\
\text { graficamente) para a ampliação e a escolha do } \\
\text { vocabulário em campos de palavras. Esses campos são } \\
\text { indicados no sumário. } \\
\text { 10.3. Há uma apresentação contínua para a exploração } \\
\text { e/ou a memorização do vocabulário } \\
\text { Indicador: respectivas dicas no sumário, introdução dos } \\
\text { internacionalismos mais frequentes nos capítulos } \\
\text { iniciais, dicas nos livros para os professores. } \\
\text { 10.4. Levando em consideração os processos mentais } \\
\text { em relação ao léxico, treina-se o vocabulário, sobretudo } \\
\text { de maneira associativa e em contextos de ações } \\
\text { linguísticas. } \\
\text { Indicador: utilização de vocabulário focalizada para a } \\
\text { comunicação de algo; trabalho com o vocabulário } \\
\text { receptivo, com textos autênticos; consideração de } \\
\text { colocações e co-ocorrências (uso vinculado de termos) }\end{array}$ & $\ldots 1 \ldots$ & ......... & ........ \\
\hline Q11 & $\begin{array}{l}\text { Conteúdos / aspectos culturais } \\
\text { 11.1. De acordo com os temas sugeridos dos níveis de } \\
\text { competência europeus, transmite-se conhecimentos } \\
\text { culturais explícitos e implícitos } \\
\text { Indicador: sumário, temas, fotos, entrevistas com } \\
\text { pessoas reais e com opiniões divergentes } \\
\text { 11.2. Ao lado do significado pragmático do estudo de } \\
\text { aspectos culturais, é também objetivo de aprendizagem } \\
\text { intercultural a sensibilização para percepção da sua } \\
\text { própria cultura e da cultura da outra língua } \\
\text { Indicador: tarefas que focalizam questões e atitudes dos } \\
\text { aprendizes, a tematização explícita de plurilinguismo e } \\
\text { compreensão intercultural. O livro sugere discussões } \\
\text { sobre imagens do outro e autoimagens, tanto } \\
\text { culturais quanto nacionais. } \\
\text { 11.3. Consideração da motivação dos aprendizes, isto é, } \\
\text { a integração da aprendizagem de uma língua estrangeira } \\
\text { com finalidades profissionais } \\
\text { Indicador: ações comunicativas gerais (p. ex., marcar } \\
\text { compromissos) são introduzidas em âmbitos } \\
\text { profissionais, tematização de imaginários de diversas } \\
\text { profissões do cotidiano (introduzir as profissões não } \\
\text { apenas como vocabulário) } \\
\text { 11.4. O material considera todos os países onde a } \\
\text { língua estudada é falada } \\
\text { Indicador: no sumário e nas lições aparecem todos os } \\
\text { países da língua alvo } \\
\text { 11.5. A aprendizagem cultural é sustentada com a }\end{array}$ & $\ldots 2 \ldots$ & ......... & ......... \\
\hline
\end{tabular}




\begin{tabular}{|c|c|c|c|c|}
\hline & $\begin{array}{l}\text { inserção de diversos gêneros textuais de interesse } \\
\text { para os alunos } \\
\text { Indicador: no livro, encontram-se textos autênticos } \\
\text { de diferentes gêneros: textos literários, jornalísticos } \\
\text { etc. }\end{array}$ & $\ldots 2 \ldots$ & & ......... \\
\hline Q12 & $\begin{array}{l}\text { Avaliação / autoavaliação } \\
\text { 12.1. A avaliação do processo e do resultado da } \\
\text { aprendizagem é parte integral do material didático. } \\
\text { Indicador: o livro contém formulações claras dos } \\
\text { objetivos da aprendizagem e, em cada capítulo, há um } \\
\text { resumo/retrospectiva daquilo que foi alcançado. Em } \\
\text { intervalos regulares sugere-se a autoavaliação. O livro } \\
\text { contém materiais de treinamento para provas e testes. }\end{array}$ &. $.1 \ldots$ & ......... & $\ldots \ldots$ \\
\hline
\end{tabular}

